Titulo do Trabalho

\title{
GÊNEROS DE ALGAS DE ÁGUA DOCE E CIANOBACTÉRIAS IDENTIFICADOS NOS CORPOS D'ÁGUA DA CASCALHEIRA-TRÊS LAGOAS/MS- 2013.
}

Nome do Autor (a) Principal

\section{Priscilla de Andrade Delite}

Nome (s) do Coautor (a) (s)

Rony Carlos Barcelos Blini

Nome do orientador

Maria José Neto

Instituição ou Empresa

Universidade Federal de Mato Grosso do Sul

E-mail de contato

tisilica@yahoo.com.br

Palavras-chave

Algas. Cascalheira. Fitoplâncton.

\section{INTRODUÇÃO}

O termo "alga" foi proposto oficialmente como uma categoria taxonômica em 1753, por Lineu, no clássico Species Plantarum. Apresentado no plural como Algae em latim significa "sementes marinhas", constituem um grande e diversificado grupo de espécies autotróficas, ou seja, que produzem a energia necessária ao seu metabolismo por meio da fotossíntese, sendo unicelular ou multicelular. Muitas algas são seres fotossintetizantes apesar de terem estruturas simples, uma vez que não possuem algumas estruturas e organelas presentes nas plantas terrestres. Mesmo as 
que apresentam tecidos diferenciados não possuem raízes, caules ou folhas verdadeiras Atualmente, são conhecidos por algas os organismos talófitos e protistas clorofilados, e inclusive alguns não pigmentados, cujos órgãos de reprodução jamais são envoltos por um conjunto ou tecidos constituído de células estéreis (BICUDO; MENEZES, 2005).

Com o advento da moderna tecnologia, o grau da interferência humana no ambiente aumentou de maneira assustadora; atualmente, são poucos os sistemas de drenagem, no mundo inteiro, que têm caráter inteiramente natural. Embora o controle dos sistemas hidrológicos seja maior nos países desenvolvidos, as modificações inadvertidas dos mesmos sistemas são universais, em geral pelo modo de uso da terra (DREW, 2005).

Na década de 1960, fruto da necessidade nacional de geração de energia, edificou-se no município de Três Lagoas MS, a Usina Hidrelétrica Engenheiro Souza Dias (Jupiá). Para está obra, bem como para vários empreendimentos correlatos e subsequentes, foram extraídos do substrato local, toneladas de matéria-prima mineral. A maior parte das áreas residuais da referida exploração, permanecem como depósitos de rejeitos e escaves profundos sem qualquer tipo de recuperação ambiental. Após o termino da construção da usina hidroelétrica, a área utilizada para a remoção de cascalho durante a construção se tornou uma área de segurança, sob os cuidados do Exército e com isso foi utilizada para treinamentos militares. Desde este período, parte da área menos afetada se recuperou e nas proximidades o Cerrado voltou a crescer, tanto que abriga o Parque Municipal das Capivaras. O local poderia ser um ponto turístico de Três Lagoas, uma vez que, desde 2004 não é mais área de segurança.

No local foi escavado um canal para o desvio das águas do rio Sucuriú durante a construção da mesma usina hidroelétrica e devido à proximidade da superfície dos lençóis freáticos da região, os buracos escavados se encheram de água ao longo do tempo, formando lagoas que propiciaram a presença de macrófitas, peixes, organismos aquáticos de modo geral e principalmente algas objeto de estudo deste trabalho. O objetivo principal foi, a coleta e a identificação da diversidade de 
algas encontradas nas lagoas locais, visando buscar parâmetros que permitam diagnosticar se o ecossistema vem sendo recuperado.

\section{OBJETIVO GERAL}

Verificar a biodiversidade aquática da área da Cascalheira-Três Lagoas/MS

\section{OBJETIVOS ESPECÍFICOS}

Identificar os gêneros de algas e cianobactérias dos corpos d'água da Cascalheira para o ano de 2013

\section{METODOLOGIA}

A área de estudo localiza-se na intersecção dos rios Sucuriú e Paraná, no município de Três Lagoas-MS. É um complexo formado por várias lagoas denominado Cascalheira, cujas coordenadas geográficas são: Latitude $20^{\circ} 45^{\prime} 26.67 " \mathrm{~S}$ e Longitude 513'ㄹ' $28.75^{\prime \prime O}$.

Para a coleta do material biológico foram realizadas três campanhas que compreenderam aos seguintes períodos: mês de abril com ausência de precipitações e temperatura em torno dos $25^{\circ} \mathrm{C}$; mês de julho, também com ausência de chuvas, mas com a temperatura mais amena, em torno de $19{ }^{\circ} \mathrm{C}$ e a última no mês de setembro sob temperatura de $28^{\circ} \mathrm{C}$ e com chuva nos dias que antecederam a coleta, todas no ano de 2013 e nos períodos matutinos.

As coletas foram feitas em diferentes pontos com auxilio de uma rede planctônica e em seguida colocado em recipientes de vidro com tampa e levadas ao laboratório. As amostras foram observadas em um microscópio óptico binocular Olympus CX40 nos aumentos de 100x e 200x, com o material ainda fresco de acordo com Bicudo; Menezes (2005). Foram preparadas em média 20 lâminas, que foram registradas por meio de fotografias digitais em média resoluções para futuras identificações. Apesar do material ter sido analisado logo após a coleta, uma parte foi fixada em álcool a $50 \%$ para posteriores revisões. 
A identificação do material, em laboratório, deu-se por comparação com literaturas específicas, entre elas Bicudo; Menezes (2005) e Sant'Anna et al. (2012).

\section{RESULTADO (S)}

Foram identificados 84 gêneros distribuídos em sete grandes grupos denominados taxonomicamente de Classes, desta forma, o fitoplâncton da cascalheira ficou distribuído conforme a seguir: Bacillariophyceae (24 gêneros: Achnanthes, Achnanthidium, Amphipleura, Amphora, Aulacoseira, Cocconeis, Craticula, Cymatopleura, Cymbella, Diatoma, Eunotia, Frustulia, Gomphonema, Gyrosigma, Melosira, Navícula, Nitzschia, Pinnularia, Stauroneis, Surirella, Synedra, Tabellaria, Ulnária, Urosolenia); Chlorophyceae (30 gêneros: Ankistrodesmus, Chlamydomonas, Chlorella, Chodatella, Choricystis, Cladophora, Coelastrum, Desmodesmus, Draparnaldia, Elakatothrix, Eudorina, Eutetramorus, Gloeocystis, Golenkinia, Kirchneriella, Micractinium, Monoraphidium, Oedogonium, Oocystis, Pediastrum, Planktosphaeria, Scenedesmus, Schizomeris, Schroederia, Tetradesmus, Tetraëdron, Tetrallantos, Tetrastrum, Treubaria, Ulothrix); Chrysophyceae (2 gêneros: Mallomonas, Synura); Cryptophyceae (3 gêneros: Chroomonas, Cryptomonas, Rhodomonas); Cyanophyceae (7 gêneros: Anabaena, Cylindrospermopsis, Hapalosiphon, Merismopedia, Microcystis, Oscillatoria, Phormidium); Euglenophyceae (1 gênero: Euglena) e Zygnomaphyceae ( 17 gêneros: Bambusina, Closterium, Cosmarium, Desmidium, Euastrum, Gonatozygon, Micrasterias, Mougeotia, Netrium, Sphaerozosma, Spirogyra, Spondylosium, Staurastrum, Staurodesmus, Teilingia, Zygnema, Zygogonium). Os dados obtidos permitiram concluir que a composição do fitoplâncton das lagoas do complexo da Cascalheira é relativamente similar aos lagos de inundação de outras áreas do Brasil, de acordo com Henry et al, 2006, normalmente constituída pelos grandes grupos táxonônomicos, predominantemente pelas classes Euglenophyceae e Chlorophyceae, como no Lago Castelo e no Rio Paraguai (OLIVEIRA; CALHEIROS, 2000), por Chlorophyceae e Bacillariophyceae como no Rio Baía no Alto Paraná (TRAIN; 
RODRIGUES, 1998), e por Zygnemaphyceae e Chlorophyceae na Lagoa Albuquerque no Pantanal conforme Espíndola et al. (1996).

\section{CONSIDERAÇÕES FINAIS}

Numericamente as classes mais representativas coincidem com os trabalhos citados, as demais classes encontradas com baixo percentual indicam ser particularidades da área em questão.

Durante as observações notou-se que apesar de terem sido realizadas três campanhas em estações distintas e pontuais, não houve variações dos gêneros encontrados nas diferentes coletas, portanto, as análises apresentam resultados referentes às médias dos seis pontos de coleta. Quanto aos períodos de coleta, observou-se que de uma campanha para outra o material amostrado foi mais abundante quanto ao número de indivíduos na campanha final, sob precipitações e temperatura mais elevada.

A presença destes organismos pode indicar que o ambiente está em recuperação, mas sugere-se a continuidade deste trabalho para futuras comparações com outros parâmetros, principalmente com a análise físico-química da água.

\section{REFERÊNCIAS}

BICUDO, C. E. de M.; MENEZES, M. Gêneros de algas de águas continentais do Brasil: chave para identificação e descrições. Editora Rima. 2005.

DREW, D. Processos Interativos Homem - Meio Ambiente. 6a edição. Editora Bertrand Brasil. 2005.

ESPÍNDOLA, E.G., MATSUMURA-TUNDISI, T. \& MORENO,I.D. 1996. Estrutura da comunidade fitoplanctônica da lagoa Albuquerque (Pantanal Mato-grossense), Mato Grosso do Sul, Brasil. Acta Limnologica Brasiliensia 8:13-27.

HENRY, R.; USHINOHAMA, E.; FERREIRA, R.M.R.. Fitoplâncton em três lagoas marginais ao Rio Paranapanema e em sua desembocadura no Reservatório de Jurumirim (São Paulo, Brasil) durante um período prolongado de seca. Revista Brasil. Bot., V.29, n.3, p.399-414, jul.-set. 2006.

LINNAEUS, C. 1753. Species Plantarum $1^{\circ}$ ed., v.2, p.1009. The Ray Society London. (Facsimile 1959). 
OLIVEIRA, M.D. \& CALHEIROS, D.F. 2000. Flood pulse influence in phytoplankton communities of the south Pantanal floodplain, Brazil. Hydrobiologia 427:101-112.

SANT'ANNA, C.L.; TUCCI, A.; AZEVEDO, M.T.P.; MELCHER, S.S.; WERNER, V.R.; MALONE, C.F.S.; ROSSINI, E.F.; JACINAVICIUS, F.R.; HENTSCHKE, G.S.; OSTI, J.A.S.; SANTOS, K.R.S.; GAMAJÚNIOR, W.A.; ROSAL, C. \& ADAME, G. 2012. Atlas de cianobactérias e microalgas de águas continentais brasileiras. Publicação eletrônica, Instituto de Botânica, Núcleo de Pesquisa em Ficologia. www.ibot.sp.gov.br

TRAIN, S.; RODRIGUES, L.C. 1998. Temporal fluctuations of the phytoplankton community of the Baia River, in the upper Paraná River floodplain, Mato Grosso do Sul, Brazil. Hydrobiologia 361:125-134. 